\title{
Investigation on the Application of Plastic Fibres as Reinforcing Materials In Concrete ${ }^{1}$ Ajamu S. O., ${ }^{2}$ Isola S. K. and ${ }^{* 3}$ Ige J. A. \\ ${ }^{1,2,3}$ Department Of Civil Engineering, Ladoke Akintola University of Technology, PMB 4000 Ogbomoso, Oyo State Nigeria \\ *Corresponding Author: jaige@lautech.edu.ng (+2347038065010)
}

\begin{abstract}
Reinforcing materials in concrete are employed to enhance the tensile strength because concrete is weak in tension. Existing reinforcing materials have inadequate ductility and inability to reduce concrete cancer (corrosion) which can be addressed by using plastic fibre because of high ductility and inertness. Hence, this research assessed the effect of plastic fibre as reinforcement in concrete. Polyethylene terephthalate materials were obtained from Aradaa Market, Ogbomoso, Nigeria and shredded into fibre size of $65 \times 2 \mathrm{~mm}$. The shredded fibre introduced into the concrete mix ratio 1:2:4 using $12 \mathrm{~mm}$ aggregate size at $0.5,1.5$ and $2.5 \%$ volume fraction of the total mass of the concrete composite. The workability of the concrete produced was assessed in the laboratory through slump test. Plastic fibre reinforced concrete cubes of size $150 \times 150 \times 150 \mathrm{~mm}$ and beams of size $100 \times 100 \times 500 \mathrm{~mm}$ were produced in line with British Standard 882, Part 1 specification. The compressive and flexural strengths of these reinforced concrete composites were examined with the compressive test machine and Universal Testing Machine after 28 days of curing. The crack examination test on plastic fibre reinforced concrete was also done with the use of crack comparator. The slump values varied from 3-60 mm height. Compressive strength of the cubes varied from 18.58 to $18.71,8.18$ to 8.22 , and 2.22 to $2.27 \mathrm{~N} / \mathrm{mm}^{2}$ for $0.5,1.5$ and $2.5 \%$ volume fraction, respectively. The corresponding flexural strength test values of the beams ranged from 23.95 to $24.01,12.01$ to 12.07 and 4.94 to $5.80 \mathrm{~N} / \mathrm{mm}^{2}$, respectively. The crack examination test revealed crack width of $0.05 \mathrm{~mm}$ on the plain $(0 \%$ fibre) concrete cubes while those with fibre reinforcement showed no cracks. Fibres reinforcement at $0.5 \%$ volume fraction improved the compressive and flexural strengths and reduced cracks of concrete. Shredded plastic fibres can be successfully used in many construction applications of light weight, non-load bearing and infill panels.
\end{abstract}

Keywords: Plastics fibers, fiber reinforced concrete, compressive strength, flexural strength, volume fraction

\section{Introduction}

Reinforcing material is used for inducing ductility, and to control cracks in concrete structure, (ASTM, 2015). It also play an important role in the structural strength of concrete for a number of reasons -handling tensile stresses cracks, bridging, ductility, confinement and many others, depending on the functions and types of the civil engineering infrastructures (ASTM, 2015).

Most concrete used for construction is a combination of concrete and reinforcement materials hence, its name 'reinforced concrete'. Reinforcing materials are generally designed to resist tensile stresses that might cause unacceptable cracking or structural failure in particular regions of the concrete. With this impression, reinforcement materials are embedded passively in concrete before such concrete sets (Swamy, 2015).Reinforced concrete is a composite material in which concrete's relatively low tensile strength and ductility are taken care by the inclusion of reinforcement having higher tensile strength and ductility. This implies that for reinforced concrete to serve its intended function, the said reinforcement must be of the right kind, and of the right amount and in the right place for the concrete structure to meet its requirement for strength and serviceability (Swamy, 2015).

According to Kandasamy and Murugesan (2011), concrete in general has a higher brittleness with increase in strength. This is a major drawback since brittleness can cause sudden and catastrophic failure, especially in structures, which are subjected to earthquake, blast or impact loading. This serious disadvantage of concrete can be overcome by the incorporation of steel reinforcement. With adequate force of adhesion per unit area of contact between the bonded surface of reinforcement and concrete surface plus sound interactions between these two members, the traditional steel would be able to distribute and transfer the tensile stress from the steel into the concrete, and strain force, that causes concrete to crack and ultimately fail, Elasto Plastic Concrete (EPC 2015).

Besides, Dadi et al. (2015) submitted that strength and ductility characteristics of the reinforcement steel need to govern the post-yield failure pattern and mode of failure of the reinforced concrete members. However, these two main attributes of reinforcing bars are opposite to each other. For instance, when plain reinforcing bars were used in construction, the main hindrance was their low yield strength with adequate ductility. Hence, the designed reinforced concrete section became more congested or sometimes difficult to accommodate the design reinforcement to resist impact demand (seismic) in case of earthquakes. It is this occurrence of problems that 
motivated the engineers and designers to believe that the solution to these problems lie in provision of alternatives to traditional steel fibre reinforcements (EPC, 2015).

These serious disadvantages of steel reinforcement was thought to be partially overcome with the introduction and use of fibre reinforcement materials (Kardasamy and Murugesan, 2011). The incorporation of steel fibres from arrays of fibres available according to Kandasamy and Murugesan (2011), can cause a change in the failure mode under compressive deformation from brittle to pseudo-ductile, thereby imparting a degree of toughness to concrete. While this system has been successful for many years there are a number of associated drawbacks; steel fibre is expensive, difficult to transport and store. The placement of steel fibre reinforcement consumes significant time. The most serious of all is that steel fibre is highly corrosive in nature which commonly leads to concrete 'cancer' (EPC, 2015). Concrete cancer refers to the corrosion of reinforcement leading to failure of the concrete.

Rather unfortunately, the world-wide acceptance and recognition given to steel fibres was short-lived in the construction industry due to above reasons, where the high dose rate (high volume fraction) required for changes to be made to the concrete mix and the handling steel fibres often results in punctured wounds (EPC, 2015). With this occurrence therefore, research continued desperately into viable alternatives from other series of fibres of plastic and glass that could solve steel fibre core problem of corrosion, cost and durability. Hence, the introduction of fibre reinforced concrete containing polythene fibres.

Macro synthetics fibres in the 1990s were the first synthetic fibre to offer structural benefit to concrete and were the first viable alternative to crack control in concrete. These synthetic fibres are similar in size to steel fibres and provide concrete with the same, and, often, higher level of post crack flexural capacity as steel fibres or mesh. Synthetic fibres and polymers are the simple molecular substances of plastic. From the viewpoint of construction engineers and industrial engineers, the commercially available polymer material possesses a number of very important properties such as low density, good tensile strength and impact strength, elastic modulus, inertness, and creep rate, which when included in concrete as reinforcing fibres enhances better performance of the concrete (Shestoperov, 2015).

Statistically, and progressively in 2010, plastic waste generated was approximately 31 million tons, representing $12.4 \%$ of total municipal solid waste in United State of America (Bolden et al., 2013). With this outrageous amount of solid waste, it ultimately sends bad signals to virtually all the environmental, construction and soil engineers, knowing fully well its inherent adverse effects. Recycling of such waste construction materials saves natural resources, saves energy, reduces solid waste, reduces air and water pollutant and reduces the emission of greenhouse gases (Oladejo, 2012).

In Nigeria, domestic plastic bottles waste often cause considerable damage to the environment. Hence, an attempt has been made to understand whether they can be successfully processed and be used in concrete to improve some of the mechanical properties, as in the case of the steel fibres. With the incorporation of this recycled material, the concrete's compressive strength and flexural strength would be exploited to project the use of this material in concrete works and logically, reducing the menace of environmental degradation and pollution which are often the case in most Nigerian urban and semi-urban cities.

According to Andrady (2003), plastic waste is a growing disaster. The manufacture of plastics, as well as its destructions by incineration pollute the air, land sea and often expose workers to toxic chemical carcinogens. Hence Oladejo (2013) and USEPA (2015) were of the opinions that, plastic wastes which are often taken as solid wastes need integrated Municipal Solid Waste Management Techniques, Adopted by United State Environmental Protection Agency (USEPA), with recycling as a major and critical step to be taken. This work therefore set out to investigate the possibility of using plastic fibres as a reinforcement material in concrete production as a means of disposing used plastic materials and taping from its benefiting mechanical properties.

\section{Methodology}

The material used for this work are cement, coarse aggregate, fine aggregate and water while the equipment were cube mould ( $150 \mathrm{~mm} \times 150 \mathrm{~mm} \times 150 \mathrm{~mm}$ ), shovel, trowel, cement (purchased from a retailer within Ogbomoso), used plastic water bottles. The used plastic bottles were solid wastes sourced from Aradaa market, Ogbomoso, Nigeria, while clean and drinkable water was used for the entire research work.

\section{Production of plastic fibres}

A Fibre size $60 \mathrm{~mm}$ long and $2 \mathrm{~mm}$ wide with $1 \mathrm{~mm}$ thickness was produced. Quantity of fibres needed for the 
$0.5 \% 1.5 \%$ and $2.5 \%$ volume fraction were obtained and stored.

\section{Coarse aggregate gradation analysis}

Sieve analysis was performed on the coarse using standard BS sieve size and procedures as outlined in BS 812:103

\section{Production of plastic fibre reinforced concrete and test specimens}

Fresh concrete with average particle size of coarse aggregate of $12 \mathrm{~mm}$ and mix ratio 1:2:4 was produced in conformity with BS 1881-125:1986 in the laboratory. Different specimen of fibre reinforced fresh concrete were then produced by addition of prepared plastic fibre at different volume fractions $\left(\mathrm{V}_{\mathrm{f}}\right)$ of $0.5 \%, 1.5 \%$ and $2.5 \%$ and were mixed thoroughly and uniformly with the concrete paste with the use of shovel.

The cube moulds were assembled and tightened. The internal surface were cleaned and thinly coated with mould oil to prevent adhesion of concrete to mould. The specimens were placed in the concrete cube moulds in accordance with BS 1881-108:1983 and into beam moulds (in line with the provision of BS EN 12390-5 2009) with the use of trowels and compacted with 35 strokes and placed in the moist air for 20 hours and later demoulded to be submerged in the curing tank for 28 days. Figure 1 shows progressive activities involved in the production of plastic fibre reinforced concrete.

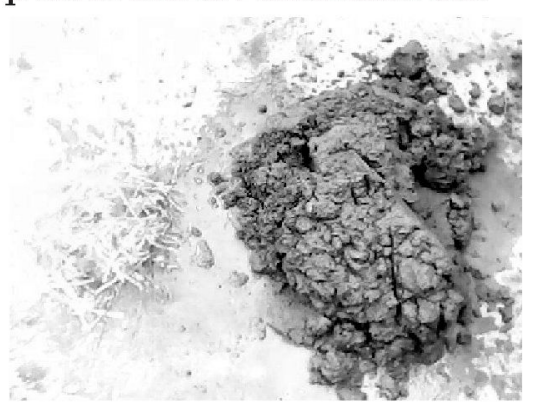

Figure 1a: Plastic fibres and wet concrete before mixing

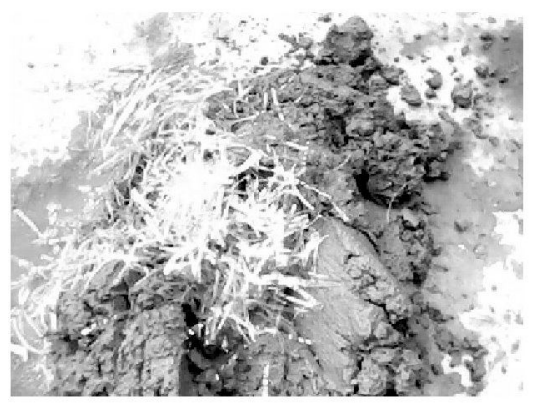

Figure 1b: Mixing of wet concrete with plastic fibres

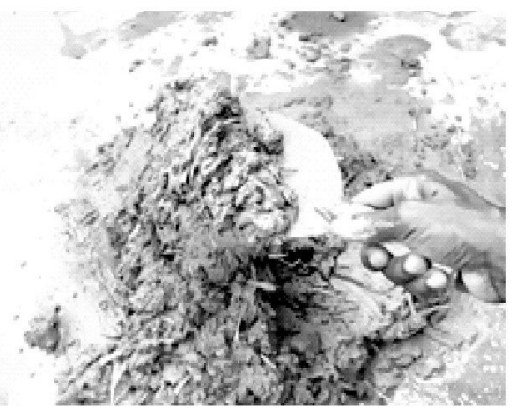

Figure 1c: Plastic fibre reinforced concrete after mixing

\section{Slump test}

The slump test was carried out with the fresh fibre reinforced concrete in accordance with the prescribed procedures outlined in BS1881-102(1983). The most stable slump cone average height was recorded.

Description of the compressive and flexural strength tests

The compressive strength test was carried out on a compressive test machine with maximum loading capacity of $1500 \mathrm{kN}$ (Controls Milano-Italy, range: $0-1500 \mathrm{kN}$ ) and flexural strength tests were carried out on universal tensile machine (UTM) with a load range of $600 \mathrm{kN}$ by $1 \mathrm{kN}$ division (FIE UTM $0-600 \mathrm{kN}$ ) in accordance with the procedures described in BS EN 12390-3:2002 and BS EN 12390-5:2009 respectively. Figure 2 shows a plastic reinforced concrete cube under compressive strength machine. The compressive and flexural strength obtained were calculated with the following formulae

$$
\text { Cubestrength }=\frac{F}{A}
$$

Where $F=$ Load on cube at failure $(\mathrm{N})$

$A=$ Load bearing area of the cube $\left(\mathrm{mm}^{2}\right)$

Flexural strength, $R=\frac{3 P L}{2 b d^{2}}$

Where:

$$
\begin{aligned}
& \mathrm{R}=\text { Modulation of rupture or flexural strength }\left(\mathrm{N} / \mathrm{mm}^{2}\right) \\
& \mathrm{P}=\text { Load on beam at failure }(\mathrm{kN}) \\
& \mathrm{L}=\text { Span length }(\mathrm{mm}) \\
& \mathrm{b}=\text { Average width }(\mathrm{mm}) \\
& \mathrm{d}=\text { Average depth }(\mathrm{mm})
\end{aligned}
$$




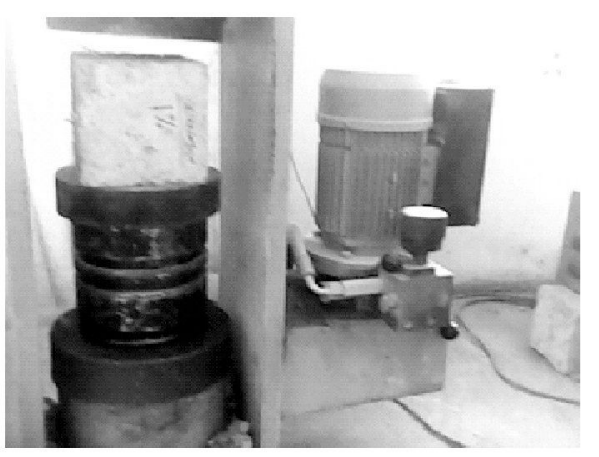

Figure 2: Plastics fibre reinforced concrete under compressive test machine (1500kN maximum load range capacity)

\section{Results and Discussion}

\section{Production of plastic fibres}

Figure 3 shows the heap of plastic fibres produced from waste plastic water bottles.

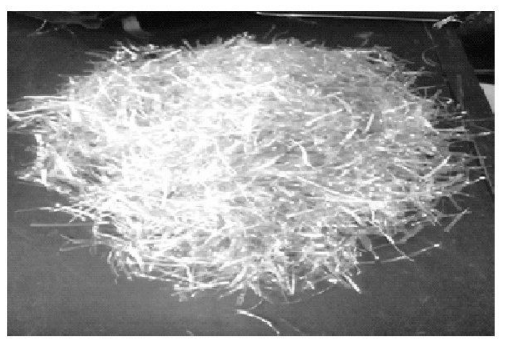

Figure 3: Heap of plastic fibres

\section{Workability of fresh concrete and production of fibre reinforced concrete}

The average slump height obtained with the use of chosen $12 \mathrm{~mm}$ coarse aggregate was $60 \mathrm{~mm}$. The curve obtained from sieve analysis of coarse aggregate of $12 \mathrm{~mm}$ size is presented in Figure 4. Samples of plastic fibre reinforced concrete cubes obtained after demoulded are presented in Figure 5.

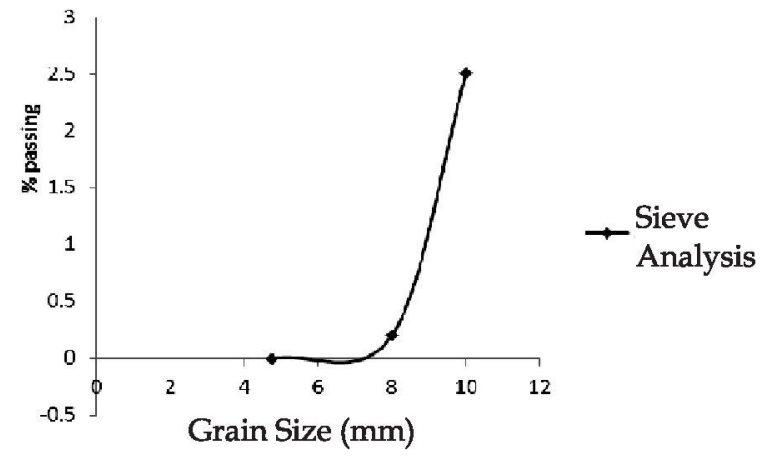

Figure 4: Particle size distribution curve for the coarse aggregate used

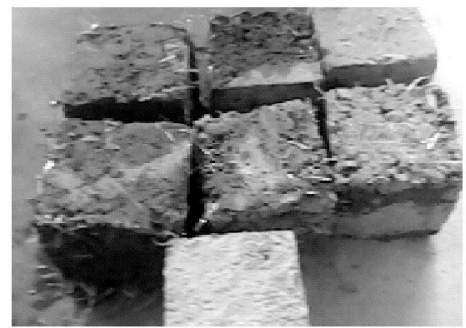

Figure 5: Plastics fibre reinforced concrete cube samples

\section{Result of compressive and flexural tests}

(i) Compressive Strength

Table 1: Results of 28 days cubes compressive strength

\begin{tabular}{cccc}
\hline$\%$ of Fibres Used & Sample No & Load (N) & Compressive Strength (N/mir \\
\hline $0 \%$ & SP1 & 310000 & 13.78 \\
& SP2 & 309000 & 13.73 \\
& SP3 & 310000 & 13.78 \\
\hline $0.5 \%$ & SC1 & 420000 & 18.67 \\
& SC2 & 418000 & 18.58 \\
& SC3 & 421000 & 18.71 \\
\hline
\end{tabular}




\begin{tabular}{lccc}
\hline $1.5 \%$ & SC1 & 185000 & 8.22 \\
& SC2 & 185000 & 8.22 \\
& SC3 & 184000 & 8.18 \\
\hline $2.5 \%$ & SC1 & 50000 & 2.22 \\
& SC2 & 51000 & 2.27 \\
& SC3 & 50000 & 2.22 \\
\hline
\end{tabular}

Table 2: Comparison of 28 days cube compressive strength at varying volume fractions

\begin{tabular}{|c|c|c|c|}
\hline \multirow[t]{2}{*}{$\begin{array}{l}\text { Volume } \\
\text { fraction }(\%)\end{array}$} & \multicolumn{2}{|c|}{$\begin{array}{l}\text { Average compressive Strength } \\
\qquad\left(\mathrm{N} / \mathrm{mm}^{2}\right)\end{array}$} & \multirow{2}{*}{$\begin{array}{l}\text { Percentage Increase in Compressive } \\
\text { Strength of Concrete }\left[\frac{c_{2}-c_{1}}{c_{1}} \times 100\right] \\
\qquad(\%)\end{array}$} \\
\hline & $\left(C_{1}\right)$ & $\left(C_{2}\right)$ & \\
\hline 0.0 & 13.76 & & \\
\hline 0.5 & & 18.65 & 35.5 \\
\hline 0.0 & 13.76 & & \\
\hline 1.5 & & 8.21 & -40 \\
\hline 0.0 & 13.76 & & \\
\hline 2.5 & & 24.24 & -84 \\
\hline
\end{tabular}

From Table 2 it can be deduced that $0.5 \%$ volume fraction of plastic fibres in the plastics reinforced concrete samples had $35.5 \%$ increase of compressive strength over plain ( $0 \%$ fibre) concrete, and that $1.5 \%$ and $2.5 \%$ volume fractions of fibres had $40 \%$ and $84 \$$ decreases of compressive strength over plain ( $0 \%$ fibre) concrete respectively. Hence, demonstrating that plastic fibres at $0.5 \%$ volume faction is a good reinforcing materials that have adequate compressive strength property.

(i) Flexural Strength

Table 3: Results of 28 days beam flexural strength

\begin{tabular}{cccc} 
\% of Fibres Used & Sample No & Crushing Load (N) & Flexural Strength $\left(\mathrm{N} / \mathrm{mm}^{2}\right)$ \\
\cline { 2 - 4 } 0 & SP1 & 295000 & 19.68 \\
& SP2 & 293000 & 19.54 \\
& SP3 & 295000 & 19.68 \\
\cline { 2 - 4 } 0.5 & ST1 & 360000 & 24.01 \\
& ST2 & 360000 & 24.01 \\
& ST3 & 359000 & 23.95 \\
\hline 1.5 & ST1 & 180000 & 12.01 \\
& ST2 & 180000 & 12.01 \\
& ST3 & 181000 & 23.95 \\
\hline 2.5 & ST 1 & 75000 & 5.00 \\
& ST2 & 72000 & 4.80 \\
& ST3 & 74000 & 4.94 \\
\hline
\end{tabular}

Table 4: Comparison of 28 days beam flexural strength of $0.5 \%$ volume fraction

\begin{tabular}{cccc}
\hline $\begin{array}{c}\text { Volume fraction } \\
(\%)\end{array}$ & $\begin{array}{c}\text { Average flexural Strength }\left(\mathrm{N} / \mathrm{mm}^{2}\right) \\
\left(\mathrm{C}_{2}\right)\end{array}$ & $\begin{array}{l}\text { Percentage Increase in Flexural Strength } \\
\text { of Concrete } \\
{\left[\frac{\mathrm{c}_{2}-c_{1}}{c_{1}} \times 100\right](\%)}\end{array}$ \\
\hline 0.0 & 19.63 & 24.01 & 22.28 \\
0.5 & 19.63 & 12.03 & -38.7 \\
0.0 & 19.63 & 4.91 & -75.0 \\
1.5 & & & \\
0.0 & & & \\
2.5 & & & \\
\hline
\end{tabular}

From Tables 4 , it can be deduced that $0.5 \%$ volume fraction $\left(V_{\mathrm{f}}\right)$ of plastic fibre in concrete had $22.18 \%$ increase in flexural strength over plain concrete of $0 \%$ fibres, and that $1.5 \%$ and $2.5 \%$ volume fraction of plastic fibres had $38.7 \%$ and $75 \%$ decreases of flexural strength respectively over plain concrete of $0 \%$ fibre. This shows that plastic fibres addition up to $0.5 \%$ volume fraction serves as a good reinforcing materials in concrete to enhance flexural 
strength property. Figure $6 \mathrm{a}$ and $6 \mathrm{~b}$ graphically present the comparison of average compressive and flexural strengths of plain ( $0 \%$ fibre) and plastic fibres reinforced concrete.

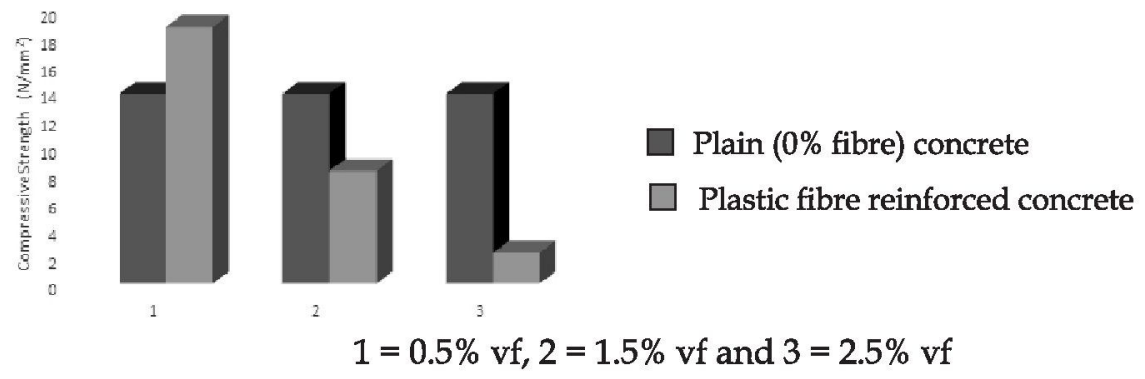

Figure 6a: Comparison of average compressive strength of plain ( $0 \%$ fibre) and plastic fibre reinforced concrete composite of age 28 days

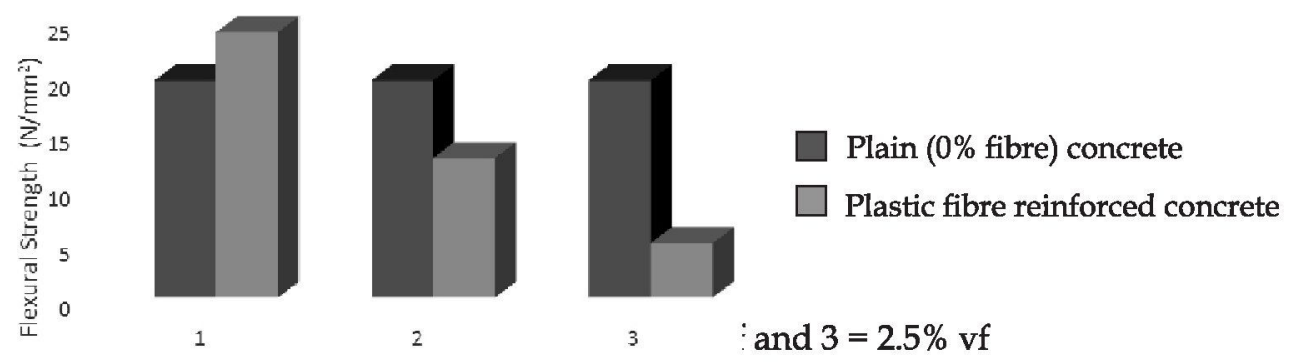

Figure 6b: Comparison of average flexural strength of plain ( $0 \%$ fibre) and plastic fibre reinforced concrete composite of age 28 days

\section{Conclusions}

Based on the findings of this study, the following conclusions could be drawn:

Plastic fibre is a suitable material for use as fibre reinforcement in concrete to control shrinkage cracks. Addition of $0.5 \%$ volume fraction to concrete increases the cube compressive strength of concrete by about $35.5 \%$ and increases the flexural strength by about $22.28 \%$. However addition of plastic fibre in concrete with $\mathrm{V}_{\mathrm{f}}$ greater than $0.5 \%$ reduces both the compressive and flexural strengths of the concrete significantly.

\section{References}

Andrady, L. A. (2003) Plastics and the Environment. Hoboken, NJ. John Wiley and Sons.

ASTM (2015). Concrete Composite, Available at www.astm.org. Accessed on 4/2/15

Bolden, J., Abu - Lebdeh, T., and Fini, E. (2013) Utilization of Recycled and Waste Materials in various Construction Application. American Journal of Environmental Science. New Califonia.9 (1): 14-24

BS EN 12390-3:2002 Part3: Compressive strength of test specimens

BS EN 12390-5:2009 Part 5: Flexural strength of test specimens

BS 1881(1983) Part 108: Method for making test cubes from fresh concrete

BS 1881-125:1986 Part 125: Methods for mixing and sampling fresh concrete in the laboratory

Dadi, V. V. S.; Surya K. and Agarwal, P. (2015). Comparative Post - Yield Performance Evaluation of Flexural Members under Monotonic and Cyclic Loadings based on Experimental Tests. The Institution of Structural Engineers, India, Elsevier Limited.

EPC (2015) the History of Fibre Reinforcement. Elasto Plastic Concrete Available at www.elastoplastic.com accessed on $\underline{4} / 2 / 2015$

Kandasamy, R. and Murugesan, R. (2011). Fibre Reinforced Concrete using Domestic Waste Plastics as Fibres. ARPN India, Asian Research Publishing Networks. Vol. 6 No3 Page 75-80.

Oladejo, O. S. (2012) Fundamentals of Environmental Engineering. Ogbomoso, (Nigeria) Infinitykoncept Multimedia Enterprises. Page 87-90.

Shestoperov, S. V. (2015). Road and Building Materials, $2^{\text {nd }}$ Edition, Mosco, Mir Publishers.

Swamy R. N., (2015) Assessing Corrosion Damage on Reinforced Concrete Structure. Available at trid.trb.org/view.aspx. Accessed on 7/8/2015.

USEPA (2005)Water Pollution DC (USA). Available atwww.epa.gov. Accessed on4/2/2015. 